\title{
Estuoses
}

IBERO-AMERICANOS

\section{A freira, a tortura e a censura: um filme de Ozualdo R. Candeias entre a crítica política e a ofensa moral}

\author{
The nun, the torture and the censorship: an Ozualdo R. Candeias' film \\ between political critique and moral offense \\ La monja, la tortura y la censura: una película de Ozualdo R. Candeias \\ entre la crítica política e lo delito moral
}

\author{
Wallace Andrioli Guedes \\ Universidade Federal de Juiz de Fora. Juiz de Fora, MG, Brasil.
}

\begin{abstract}
Resumo
O artigo analisa o filme $A$ freira e a tortura (1983), de Ozualdo R. Candeias, que aborda as sevícias impostas a uma religiosa durante os anos mais duros da ditadura militar brasileira e, ao mesmo tempo, explora situações sexuais entre personagens marginais que se encontram no cárcere. Como se trata de uma obra censurada pela Divisão de Censura de Diversões Públicas (DCDP) nos anos finais do regime ditatorial, o seu processo censório também é destrinchado no artigo, revelando os encontros e desencontros entre as censuras moral e política em um momento de transição para a democracia.
\end{abstract}

Palavras-chave: A freira e a tortura. Ditadura militar brasileira. Censura.

\begin{abstract}
This paper analyzes the movie The Nun and The Torturer (1983), directed by Ozualdo R. Candeias, which approaches the abuses imposed on a religious woman during the hardest years of the Brazilian military dictatorship, at the same time exploring the sexual encounters between other imprisoned side characters. Since the movie was censored by the Public Diversion Censorship Division (DCDP) in the final years of the dictatorship, its censoring process is also unraveled in this article, which exposes the connections and mismatches between moral and political censorships in the period of transition to democracy.
\end{abstract}

Keywords: The nun and the torturer. Brazilian military dictatorship. Censorship.

\section{Resumen}

El artículo analiza la película A freira e a tortura (1983), de Ozualdo R. Candeias, que aborda las torturas impuestas a una religiosa durante los años más duros de la dictadura militar brasileña y, al mismo tiempo, explora situaciones sexuales entre personajes marginales que se encuentran en la cárcel. Como se trata de una obra censurada por la División de Censura de Diversiones Públicas (DCDP) en los años finales del régimen dictatorial, su proceso censorio también está desintegrado en el artículo, revelando los encuentros y desencuentros entre censuras moral y política en un momento de transición a la democracia. Palabras clave: A freira e a tortura. Dictadura militar brasileña. Censura. 


\section{Introdução}

O presente artigo, derivado de pesquisas de doutorado, desenvolvida na Universidade Federal Fluminense, e de pós-doutorado, ainda em curso no Programa de Pós-Graduação em História da Universidade Federal de Juiz de Fora, lança luz sobre o caso da censura do filme $A$ freira e a tortura (Ozualdo R. Candeias, 1983), no contexto transicional da ditadura militar para a democracia no Brasil. Para isso, recorre ao processo censório da obra, depositado no fundo da Divisão de Censura de Diversões Públicas (DCDP) no Arquivo Nacional, em Brasília. Inicialmente, faz-se também breve análise do filme em si, importante para o entendimento de sua inserção no cinema brasileiro do período, destacando a sua relação com o restante da filmografia de Candeias.

Os últimos anos da ditadura militar brasileira, sobretudo aqueles que se iniciaram com a revogação do Ato Institucional número 5 (13 de outubro de 1978) e a aprovação da Lei da Anistia (agosto de 1979), foram marcados pelo crescimento de uma produção cinematográfica que tematizou o período mais duro do regime, tratando abertamente de temas como a tortura e a luta armada. Se até o final da década de 1970 os órgãos responsáveis pela censura de diversões públicas tendiam a vetar filmes políticos com esse conteúdo, a regulamentação, também em 1979, do Conselho Superior de Censura (CSC), instância recursal composta por membros do governo e da sociedade civil, permitiu não só a liberação de obras há anos proibidas ${ }^{1}$, como tornou menores as chances de interdição total de lançamentos que criticavam a ditadura.

Em 1980, por exemplo, E agora, José? Tortura do sexo (Ody Fraga, 1980) narrou a história de um homem de classe média "apolítico" que, tomado por "terrorista" por agentes da repressão, é preso, torturado e morto. Produzido na Boca do Lixo, em São Paulo, e combinando crítica política à exploração do sexo, o filme foi liberado sem cortes pela DCDP, naquele momento comandada por José Vieira Madeira. No ano anterior, Paula - A história de uma subversiva (Francisco Ramalho Jr., 1979), foi lançado nos cinemas também sem qualquer problema com a censura, tendo como protagonista Marco Antônio, um arquiteto

\footnotetext{
1 Inimá Simões (1999, p. 209) ressalta que alguns desses filmes "nunca foram oficialmente proibidos pela censura, pois jamais passaram pela avaliação desse setor da Polícia Federal. O fato ocorreu porque os distribuidores, já habituados com os vetos, evitavam importar filmes que, de acordo com um suposto critério dos censores, não poderiam chegar às telas brasileiras".
}

ex-militante do Partido Comunista que, no início da década de 1970, envolveu-se amorosamente com uma aluna sua que atuava na luta armada. A narrativa transcorre em dois momentos: o presente (final dos anos 1970), quando Marco Antônio é um profissional estabelecido em sua área que tem de lidar com o fato de estar realizando um projeto para o governo - o mesmo governo que ele combatera há alguns anos e com o desaparecimento de sua filha adolescente, o que o obriga a recorrer ao delegado, ex-torturador do DOPS, responsável pela morte de sua jovem amante; e o passado (1968 a 1971), quando o personagem conhece e se envolve com Paula e ambos sofrem com a repressão.

No entanto, ainda durante a abertura política conduzida pelo governo do general João Figueiredo (1979-1985) alguns filmes foram interditados ou cortados por seu conteúdo crítico ao regime. O caso mais conhecido é o de Pra frente, Brasil (Roberto Farias, 1982), cuja história se assemelha bastante à de E agora, José? Tortura do sexo: um sujeito sem qualquer engajamento ou interesse pela política do país é fortuitamente tomado por guerrilheiro e sequestrado por um grupo paramilitar de direita, que o tortura até a morte. Dirigido por um ex-presidente da Embrafilme e com elenco de atores conhecidos por sua atuação em telenovelas (Reginaldo Faria, Antônio Fagundes, Elizabeth Savalla, Carlos Zara, Natália do Valle, Paulo Porto, Cláudio Marzo, entre outros), Pra frente, Brasil foi inicialmente liberado para exibição em dois importantes festivais de cinema (o de Gramado, no Rio Grande do Sul, do qual saiu premiado como melhor filme, e o de Cannes, na França) e para o circuito comercial brasileiro pelos técnicos de censura, mas posteriormente vetado para esse último por decisão direta da então diretora da DCDP, Solange Hernandes.

A proibição da estreia do filme de Roberto Farias repercutiu bastante na imprensa, em um momento de liberalização censória relativa principalmente a conteúdos políticos. Após recurso ao CSC, Pra frente, Brasil foi enfim liberado, estreando nos cinemas do País quase um ano após a sua primeira exibição (fevereiro de 1983) ${ }^{2}$.

Outros filmes brasileiros de conteúdo crítico à ditadura militar encontraram dificuldades com a censura durante a gestão de Hernandes na DCDP (e de Ibrahim Abi-Ackel no Ministério da Justiça). Foram os casos de A próxima vítima (João Batista de Andrade,

2 Sobre os detalhes do processo censório de Pra frente, Brasil, Cf. GUEDES, 2015. 
1983) e Em nome da segurança nacional (Renato Tapajós, 1984). Ao primeiro, um thriller sobre uma série de assassinatos de prostitutas no bairro do Brás, em São Paulo, foram determinados cortes em cenas que representavam negativamente as instituições policiais e que comentavam o momento político do Brasil (a narrativa de A próxima vítima transcorre durante a campanha eleitoral para governador, em 1982) ${ }^{3}$.

Já o segundo, documentário de registro da atuação do Tribunal Tiradentes, organismo da sociedade civil criado com o intuito de julgar simbolicamente a Lei de Segurança Nacional, não recebeu dos censores, quando analisado em 1984, sequer um parecer favorável. Foi interditado, curiosamente, por ser considerado uma ameaça à segurança nacional.

Após recorrer, em vão, ao diretor do Departamento de Polícia Federal (DPF), a empresa produtora do filme apelou para o CSC, mas mesmo o supostamente liberal conselho vetou a sua exibição em cinemas e cineclubes. Em nome da segurança nacional só foi liberado em 1985, já no contexto da chamada Nova República - ainda assim, com exigência do corte de uma cena que intercala torturas com desfiles militares.

A passagem das gestões de Petrônio Portella e José Vieira Madeira para as de Ibrahim Abi-Ackel e Solange Hernandes, respectivamente no Ministério da Justiça e na DCDP, poderia justificar essa mudança na atenção dispensada a conteúdos políticos nos filmes, levando à liberação sem cortes de Paula - A história de uma subversiva e E agora, José? Tortura do sexo, em 1979 e 1980, e a interdição ou determinação de cortes em Pra frente, Brasil, A próxima vítima e Em nome da segurança nacional, em 1982, 1983 e 1984. Mas, vale considerar ainda que, mesmo nesse segundo momento, alguns filmes com claro cunho político, como $O$ bom burguês (Oswaldo Caldeira, 1983) e Nunca fomos tão felizes (Murilo Salles, 1984), passaram incólumes pela censura. Ambos foram liberados para maiores de dezoito anos, em razão das cenas de nudez, sexo e violência.

Nesse contexto de idas e vindas censórias, de um suposto recuo da censura política em detrimento daquela de cunho moral, mas no qual a primeira continua atuante sobretudo sob a dupla Abi-Ackel/ Hernandes, foi lançado (e proibido) o filme $A$ freira $e$ a tortura, de Ozualdo R. Candeias.

3 Sobre os detalhes do processo censório de A próxima vítima, $\mathrm{Cf}$. GUEDES, 2018.

\section{O filme}

A freira e a tortura narra o encontro entre uma religiosa (Vera Gimenez), que realiza trabalhos sociais na favela, e um delegado de polícia (David Cardoso), que vê nas ações da mulher uma forma de subversão. A história se passa no início da década de 1970, "anos de chumbo" da ditadura militar brasileira. Presa, a freira é torturada física e psicologicamente em um cárcere ocupado por marginais sociais típicos do cinema de Candeias. O diretor insere referências a esse contexto político autoritário logo no início do filme, quando a protagonista está em casa com os pais e lê uma edição do jornal $O$ Estado de S. Paulo em que uma notícia censurada foi substituída por um poema de Bocage. Ao lhe entregar o jornal, o pai demonstra consciência da existência da censura à imprensa: "Dá uma lida aí. Você que gosta de Camões e tudo mais, hoje está muito bom. As notícias devem estar de lascar!"4.

Em outros momentos, há referências aos esquadrões da morte (o delegado e seus dois subordinados diretos executam sumariamente um dos alunos da freira, morador da favela) e o uso de certos termos pelos personagens que remetem às lutas políticas da época: quando um frade vai até a delegacia à procura da freira desaparecida, outro policial fala, reclamando de seu colega de profissão, que aquele não é lugar de "presos políticos"; na conversa que se segue, o delegado comenta com o religioso sobre os perigos do tempo em que vivem, em razão da "subversão" e do "terrorismo". Posteriormente, o mesmo personagem cita o caso de uma estudante torturada e violentada pela polícia e, já próximo ao final do filme, há uma passagem na qual um quadro do presidente Emílio Garrastazu Médici é carregado pelas dependências da delegacia por um funcionário corcunda (Edio Smanio).

No entanto, Candeias, adaptando a peça de Jorge Andrade, submete tais referências políticas à temática sexual, já que surge uma irresistível atração entre torturador e torturada. Na verdade, outros personagens de $A$ freira e a tortura, como os demais prisioneiros, o carcereiro, o funcionário corcunda e o escrivão também se envolvem em relações sexuais ao longo do filme, que tomam mais tempo da narrativa do que qualquer discussão sobre a tortura de religiosos progressistas durante a ditadura militar. E, a própria presença no papel principal de David Cardoso, ator associado ao cinema erótico produzido ao longo das décadas de 1970

4 Transcrição de trecho de diálogo do filme $A$ freira e a tortura (1983) 
e 1980, na Boca do Lixo, reforça essa predisposição do filme. Nesse sentido, ele se assemelha a E agora, José? Tortura do sexo, cujas inserções sexuais, segundo Caroline Gomes Leme (2013, p. 15), tornam "tênue a linha que separa a denúncia da violência, de um lado, e sua apologia, de outro - especialmente no que diz respeito às personagens femininas".

Como legítimo representante das pornochanchadas produzidas em São Paulo, o longa-metragem de Fraga exibe os corpos nus de suas personagens femininas "durante praticamente todo o filme, sendo explorados pela câmera de maneira voyeurista, característica dos filmes eróticos voltados para o público masculino" (LEME, 2013, p. 15). Assim, ressalta a autora, apesar de abordar um tema - a tortura - em que corpos despidos são comuns, E agora, José? Tortura do sexo opta por esconder o nu masculino através dos enquadramentos de câmera e da manipulação de luz e sombras, "enquanto os corpos femininos - que são maioria (três mulheres) - são continuamente explorados, ao estilo característico das pornochanchadas, que privilegiam a perspectiva masculina" (LEME, 2013, p. 16-17).

Não é exatamente isso que ocorre em $A$ freira e a tortura. À exceção de David Cardoso e Vera Gimenez, os corpos mostrados por Candeias, masculinos e femininos (sempre em ambientes muito bem iluminados), carregam características que os afastam de padrões de beleza vigentes. A prostituta encarcerada é gorda. O carcereiro é velho e seu intérprete, Sérgio Hingst, caracterizado com dentaduras postiças que tornam seu sorriso grotesco. O escrivão, banguela em determinado momento o diretor faz questão de aproximar, com um zoom, sua câmera do sorriso do personagem. O outro funcionário da cadeia é corcunda e, quando excitado, se comporta com gestos e barulhos animalescos.

Assim, ainda que a existência de muitas cenas de nudez e sexo no cárcere posicione o filme próximo a $E$ agora, José? Tortura do sexo e ao que Leme chama de gênero Women in Prison ${ }^{5}$, elas estão em sintonia com a obra de Candeias, povoada de "gente feia, desdentada, pé-de-chinelo" (NETO; TOLENTINO, 2007, p. 152) e de um olhar para a realidade de miséria do País que trafega entre a crueza e o grotesco. O diretor claramente simpatiza com alguns desses personagens: a mulher emprisionada verbaliza o seu abandono, dizendo preferir a cadeia ao mundo externo, em que não tem

5 Segundo a autora, "subgênero do chamado cinema exploitation, fortemente misógino, que explora situações sórdidas envolvendo corpos femininos submetidos ao confinamento" (LEME, 2013, p. 17). para onde ir; o prisioneiro chamado de "taradão", ao ser posto na cela da freira, revela o seu passado no juizado de menores, remetendo a toda uma trajetória de vida às margens da sociedade.

É um tratamento dado à sexualidade divergente também daquele presente nos citados filmes políticos O bom burguês e Nunca fomos tão felizes, cujas cenas de sexo justificaram, em parte, sua classificação etária máxima pela DCDP - mas não foram consideradas suficientemente ofensivas para levar à proibição. As do primeiro envolvem o protagonista Lucas (José Wilker) e sua esposa (Betty Faria); o mesmo sujeito e uma amante (Nicole Puzzi); e um casal de jovens guerrilheiros (Cristiane Torloni e Anselmo Vasconcelos). Todas são acompanhadas por uma trilha sonora de saxofone que evoca sensualidade e há nelas uma exploração dos corpos, especialmente os femininos, pela câmera, com ênfase no prazer genuíno experimentado pelos personagens. Já a do segundo filme traz o protagonista Gabriel (Roberto Bataglin) perdendo a virgindade com uma prostituta. Ele age violentamente com a mulher, a relação inclusive borra as fronteiras entre o sexo consensual e o estupro, o prazer não está em foco, apesar de a câmera do diretor Murilo Salles não deixar de explorar a presença de dois belos corpos nus em cena. Em outros momentos de Nunca fomos tão felizes, mulheres, também nuas, são vistas com destaque na boate frequentada por Gabriel.

É possível dizer, portanto, que esses dois filmes se relacionam com o sexo e a nudez de forma bem mais próxima dos padrões do cinema brasileiro da época - evocando a sensualidade e o prazer e explorando os corpos femininos - do que o faz Candeias, sempre propenso ao grotesco e a destacar o que está às margens do bom gosto. Um filme como A freira e a tortura parece excessivo, nesse sentido, mesmo dentro de um cinema altamente sexualizado e nem sempre realizado com vultosos recursos.

No que concerne à política, $O$ bom burguês é um filme que aborda temas muito semelhantes aos de Pra frente, Brasil e aparenta ter se beneficiado indiretamente da controversa interdição desse último, ainda que seu diretor, Oswaldo Caldeira, tenha enfatizado o contrário, apontando para um risco de que obras próximas a de Farias recebessem o mesmo destino na DCDP 6 . Quando analisados os pareceres censórios de O bom burguês, salta aos olhos o destaque

\footnotetext{
6 "Foi uma barra muito pesada fazer $O$ bom burguês na época da ditadura militar. O Pra frente, Brasil do Roberto Farias tinha acabado de ser proibido e como consequência houve a queda do Celso Amorim à frente da Embrafilme. Imediatamente, um jornal
} 
positivo dado à representação negativa da luta armada, construída por Caldeira, o que pode ter atenuado, aos olhos dos censores, a crítica ao regime. Vale citar brevemente alguns trechos desses pareceres: "Como mensagem principal apresenta a participação do movimento comunista em ações de roubos e sequestros em passado recente do país" (Parecer no 1826/83, 11/04/1983); "Não há persuasão, pois o filme tem a intenção de retratar a fragilidade dessas organizações, bem como, os atritos e as inconformações (sic) dos membros, além de abordar que os interesses individuais, ainda, prevalecem entre eles" (Parecer no 1827/83, 12/04/1983); "A positividade da mensagem finca suas estacas no brado de alerta contra os arrivistas" (Parecer no $1828 / 83) .{ }^{7}$ E, de fato, O bom burguês apresenta a luta armada sob perspectiva bastante crítica, composta por jovens sonhadores e vazios politicamente, manipulados por lideranças autoritárias.

Nunca fomos tão felizes, por sua vez, possui uma narrativa lacônica, em que os acontecimentos políticos do País atuam como um pano de fundo, geralmente, distantes para a melancólica e solitária existência do adolescente Gabriel, isolado em um amplo apartamento em Copacabana. O pai do protagonista, engajado no confronto com o regime ditatorial, jamais tem explicitadas, na diegese, as suas ações dessa natureza. Conforme observa Leme (2013, p. 245), o espectador só conhece o mesmo que Gabriel, "não há registro das reuniões políticas, dos 'pontos', das ações armadas de que se supõe que o pai participa”. A política, ainda que importante, pode parecer secundária no filme de Salles, algo reconhecido pelos censores:

Prevalecem atitudes negativas, contudo sem forte poder de persuasão [...] $\mathrm{O}$ aspecto político quanto a ação terrorista aparece na forma de noticiários em televisão, jornais, venda clandestina de armas, prisão, ferimento grave, sem impacto de violência, e, fina ironia quanto a um período governamental, inexistindo outros aspectos mais agravantes (Parecer no 2794/84).

A freira e a tortura, como Nunca fomos tão felizes, mantém a política como pano de fundo em uma narrativa

de grande circulação nacional publicou uma matéria de página inteira que apontava os filmes que poderiam sofrer o mesmo destino do Pra frente Brasil. Entre eles, estava o nosso O bom burguês" (Transcrição de trecho do depoimento de Oswaldo Caldeira para o DVD do filme $O$ bom burguês).

7 Os processos censórios nos quais constam tais pareceres estão armazenados no Fundo Divisão de Censura de Diversões Públicas, no Arquivo Nacional, em Brasília. primordialmente interessada em outras questões, mas, quando Candeias traz para primeiro plano aspectos do Brasil dos "anos de chumbo", ele aposta, novamente, em uma abordagem agressiva. A cena, anteriormente referida, do retrato de Médici é o caso mais extremo nesse sentido: trata-se da imagem de um ex-presidente e general do Exército Brasileiro, naquele momento ainda vivo (ele faleceu em 1985), associada não só a práticas violentas, mas também a figuras toscas, de comportamento por vezes bestial. O momento é breve, dura cerca de um minuto, mas há um claro tom de escárnio com Médici: o personagem corcunda entra na delegacia carregando o retrato, que ele beija e mostra para o carcereiro; os dois gargalham; o escrivão surge perguntando pelo objeto, pega-o e deixa o recinto, mas não sem antes questionar ao carcereiro se naquele dia haveria "zorra"; à resposta cochichada em seu ouvido, ele reage com outra gargalhada.

De maneira geral, a política, posta nas bocas de personagens boçais e grotescos como os policiais de A freira e a tortura, parece se descolar de qualquer conotação séria. O modelo do thriller naturalista, reproduzido em Pra frente, Brasil, O bom burguês e $A$ próxima vítima, não cabe aqui. Menos ainda a introspecção melancólica de Nunca fomos tão felizes. Candeias faz um filme de personagens grosseiros, feios e desagradáveis, que proferem diálogos primários ou, às vezes, dotados de uma pompa patética, que não parece combinar com o universo da história. O som, como de costume na filmografia do diretor, não se encontra em perfeita sincronia com as imagens, acentuando a sensação de estranhamento e rusticidade.

Vale citar alguns outros filmes de Candeias que caminham nesse mesmo sentido: em A margem (1967), cujo título manifesta os interesses sociais de seu cinema, o diretor narrou histórias de amor de personagens favelados à beira do rio Tietê; em Meu nome é Tonho (1969), a de um atirador criado por ciganos e de vida errante, que não se recorda de suas origens; em $A$ herança (1970), realizou uma versão mambembe de Hamlet, de Shakespeare, no interior do Centro-Sul brasileiro; em Zézero (1974), acompanhou a trajetória de um camponês que migra para São Paulo, se torna operário da construção civil, vivendo e trabalhando em condições precárias, enquanto sonha com o prêmio máximo da loteria esportiva; em $A$ visita do velho senhor (1976), registrou a experiência de uma prostituta que recebe um velho cliente de modos desagradáveis; em Aopção ou as rosas da estrada (1981), seguiu mulheres da zona rural que também rumam para a cidade grande e passam a se prostituir para sobreviver; por fim, em 
As bellas da Billings (1987), condensou momentos de categorias profissionais marginalizadas na maior cidade do País.

Em A freira e a tortura, esse estrato social está representado também na faxineira do mosteiro visitado pela protagonista em uma breve cena, logo no início, quando ela decide deixar a vida ascética do convento e atuar diretamente junto aos pobres; nas figuras marginais, prostitutas, cafetões e clientes que frequentam a região da Boca do Lixo em sequência também localizada no primeiro ato da narrativa trata-se, portanto, de um momento em que Candeias filma o próprio meio pelo qual circulava como cineasta, algo já feito anteriormente no curta-metragem documentário A rua chamada Triumpho 969/70 (1971); e, claro, nos alunos favelados da freira, homens e mulheres iletrados de idades diversas que sofrem com a violência policial.

Sobre a relação de Candeias com a Boca do Lixo, é importante observar que o diretor jamais enquadrou seu cinema em uma moldura erótico-cômica, reproduzida à exaustão nos filmes de baixo orçamento produzidos na região, visando ao lucro imediato. Figura histórica, associada a uma fase em que a Boca se mostrava mais aberta à experimentação, Candeias seguiu dirigindo filmes dotados de aridez estética, apesar de protagonizados por personagens populares.

Diante da marcação dessa especificidade, não se deve, todavia, descartar o restante do cinema da Boca do Lixo como desprovido de qualidades artísticas. Tratase de uma produção vasta e diversificada, no interior da qual diretores como Carlos Reichenbach, Jean Garrett, José Mojica Marins e Ody Fraga realizaram filmes com diferentes graus de sofisticação, muitas vezes equilibrando apelo erótico e complexidade narrativa, dramática e política. Sobre isso, Alessandro Gamo e Luís Alberto Rocha Melo (2018) destacam a busca de alguns cineastas por representações femininas menos simplistas, que extrapolassem a mera exploração dos corpos das atrizes - os autores citam, como exemplos, os filmes Mulher, mulher (1979), A mulher que inventou o amor (1979), O fotógrafo (1980) e Tchau, amor (1982), todos de Jean Garrett, Profissão: mulher (1982) e O gosto do pecado (1980), de Cláudio Cunha, Palácio de Vênus (1980), de Fraga, e Damas do prazer (1978), de Antonio Meliande.

\section{A censura}

Como o documentário Em nome da segurança nacional, A freira e a tortura não recebeu dos censores qualquer parecer favorável à liberação. Interditado em 1983, e, tendo seu recurso ao diretor do DPF negado, o filme de Candeias chegou ao Conselho Superior de Censura, que determinou a sua liberação para exibição nos cinemas brasileiros - sem cortes e proibido para menores de dezoito anos. Chama atenção que o filme foi, oficialmente, vetado pelos técnicos da DCDP por atentar contra a moral, já que supostamente atacava a religião católica.

De acordo com o parecer do primeiro censor (nome ilegível no documento) que analisou $A$ freira e a tortura, "a mensagem principal é positiva porque mostra a punição final do covarde delegado", mas "as mensagens secundárias são negativas porque debocham da instituição policial e da religião católica". Após listar as situações sexuais presentes no filme e destacar negativamente a presença excessiva de palavrões ("transformando os atores em verdadeiras máquinas de dizer obscenidades"), ele defende a interdição, com base no inciso II, artigo $2^{2}$, da Lei no 5.536/68, “considerando que esta obra expõe a figura de uma religiosa a situações ridículas e vexatórias, além de ofender gravemente a instituição policial".

O segundo parecer é da censora Eni Martins França Borges, que inicia reconhecendo como objetivo do filme "apresentar a imagem de um regime opressivo, disposto a perseguir e a torturar, de forma arbitrária, qualquer cidadão suspeito de subversão". Em seguida, ela liga a instituição policial mostrada por Candeias aos esquadrões da morte. Na conclusão, indica a interdição da obra, se baseando no artigo 153, parágrafo $8^{\circ}$ da Constituição Federal, o artigo

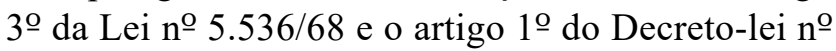
1.077/70, "por ser contrária à segurança nacional e ao regime vigente, à moral e aos bons costumes e ofende a Religião Católica".

O terceiro e último parecer censório, de autor não identificado (há apenas a assinatura do censor, sem o carimbo com seu nome como nos outros pareceres), também sugere a interdição de $A$ freira e a tortura, com base no artigo $3^{\circ}$ da Lei $n^{\circ} 5.536 / 68$, por considerar que "são depreciadas imagens representativas de segmentos de nossa sociedade".

É importante analisar o conteúdo da legislação censória utilizada nesse caso. O artigo 153 da Constituição Federal então em voga (de 1967, emendada pela Emenda Constitucional no 1 , de 17 de outubro de 1969) versa sobre os direitos e garantias individuais e, em seu parágrafo oitavo, especifica o tema da liberdade de expressão e da censura, determinando que: 
É livre a manifestação de pensamento, de convicção política ou filosófica, bem como a prestação de informação independentemente de censura, salvo quanto a diversões e espetáculos públicos, respondendo cada um, nos têrmos da lei, pelos abusos que cometer. É assegurado o direito de resposta. A publicação de livros, jornais e periódicos não depende de licença da autoridade. Não serão, porém, toleradas a propaganda de guerra, de subversão da ordem ou de preconceitos de religião, de raça ou de classe, e as publicações e exteriorizações contrárias à moral e aos bons costumes (BRASIL, 1967, grifo nosso) ${ }^{8}$.

Quanto ao Decreto-lei no 1.077/70, emblemático do período de endurecimento do regime em que foi editado, seu artigo $1^{\mathrm{O}}$ determina que "não serão toleradas as publicações e exteriorizações contrárias à moral e aos bons costumes quaisquer que sejam os meios de comunicação" .

Por fim, a lei mais citada nos pareceres, a $\mathrm{n}^{\mathrm{O}}$ 5.536/68, "dispõe sobre a censura de obras teatrais e cinematográficas, cria o Conselho Superior de Censura, e dá outras providências" (BRASIL, 1968). Seu artigo $2^{\circ}$ lista exceções na determinação de que a censura a espetáculos públicos seria estritamente classificatória, se referindo, no inciso II, a obras que possam "ofender as coletividades ou as religiões ou incentivar preconceitos de raça ou luta de classes". Já o também citado artigo 3 o determina que

Para efeito de censura classificatória de idade, ou de aprovação, total ou parcial, de obras cinematográficas de qualquer natureza levar-se-á em conta não serem elas contrárias à segurança nacional e ao regime representativo e democrático, à ordem e ao decôro públicos, aos bons costumes, ou ofensivas às coletividades ou as religiões ou, ainda, capazes de incentivar preconceitos de raça ou de lutas de classes (BRASIL, 1968, grifo nosso ${ }^{10}$.

É interessante notar, portanto, que, dos quatro artigos de leis utilizados pelos censores para justificar a interdição de $A$ freira e a tortura, apenas um, o do Decreto-lei $\mathrm{n}^{\mathrm{O}} 1.077 / 70$, não abarca tanto aspectos

\footnotetext{
8 Disponível em: http://www.planalto.gov.br/ccivil 03/Constituicao/ Emendas/Emc_anterior1988/emc01-69.htm. Acesso em: $13 \mathrm{fev}$. 2019.

9 Disponível em: http://www.planalto.gov.br/ccivil_03/DecretoLei/1965-1988/Del1077.htm. Acesso em: 19 jul. $201 \overline{4}$.

${ }^{10}$ Disponível em: http://www.planalto.gov.br/ccivil_03/LEIS/19501969/L5536.htm. Acesso em: 19 jul. 2014.
}

morais quanto políticos. Ainda assim, vale observar que essa legislação, considerada pelo jornalista Pompeu de Souza (conselheiro do CSC) o terceiro pé do tripé censório durante a ditadura militar (sendo os outros dois o Decreto no 20.493 , de 1946 e a Lei no 5.536 , de 1968), é profundamente marcada pelos princípios da Doutrina de Segurança Nacional, explicitando o entendimento da vinculação entre moral e política. Os ataques à primeira representariam, assim, uma ameaça à segurança nacional, conforme explicitado no preâmbulo do Decreto-lei:

CONSIDERANDO que a Constituição da República, no artigo $153, \S 8^{\circ}$ dispõe que não serão toleradas as publicações e exteriorizações contrárias à moral e aos costumes;

CONSIDERANDO que essa norma visa a proteger a instituição da família, preserva-lhe os valôres éticos e assegurar a formação sadia e digna da mocidade;

CONSIDERANDO, todavia, que algumas revistas fazem publicações obscenas e canais de televisão executam programas contrários à moral e aos bons costumes;

CONSIDERANDO que se tem generalizado a divulgação de livros que ofendem frontalmente à moral comum;

CONSIDERANDO que tais publicações e exteriorizações estimulam a licença, insinuam o amor livre e ameaçam destruir os valores morais da sociedade Brasileira;

CONSIDERANDO que o emprêgo dêsses meios de comunicação obedece a um plano subversivo, que põe em risco a segurança nacional (BRASIL, 1970).

A chefe da Seção de Censura Cinematográfica da DCDP, Yêda Lúcia Neto, acolheu os pareceres censórios e indicou a proibição do filme com base nos artigos supracitados, no entanto, ao se referir ao $3^{\text {o }}$ da Lei no 5.536/68, fez questão de restringir o uso da "parte específica da contrariedade aos bons costumes e ofensividade às religiões". Solange Hernandes concordou com tal pronunciamento e determinou a interdição de $A$ freira e a censura com exatamente a mesma justificativa de sua subordinada. Este é o texto do despacho de Solange Hernandes que confirma a proibição de A freira e a tortura:

I - Acolho os pronunciamentos dos Senhores Técnicos de Censura, consignadas às folhas número 05, 06 e 07, deste processado censório, assim como 
os pronunciamentos dos Senhores Chefes da SCC/ DCDP e SC/DCDP, constantes às fls. 08.

II - Em conseqüência, decido pela interdição do filme "A Freira e a Tortura", tendo em vista que a obra cinematográfica em epígrafe exterioriza temática contrária à moral, aos bons costumes e ofensiva à religião católica, com base no artigo 153, parágrafo 8 o 'in fine', da Constituição Federal, combinado com os artigos $1^{\mathrm{O}}$ e $7^{\mathrm{O}}$ do DecretoLei $1.077 / 70$ e artigo 3으, na parte específica da contrariedade aos bons costumes e da ofensividade às religiões, da Lei 5.536/68 (grifo nosso).

Hernandes, portanto, preferiu restringir-se às questões morais e religiosas para interditar um filme que também falava de política, certamente por elas, naquele momento da abertura, ainda arregimentarem algum apoio para a atuação censória. Evitava, assim, que a proibição de $A$ freira e a tortura fosse vista pela opinião pública como um caso de censura política, pouco mais de um ano após a controversa interdição de Pra frente, Brasil.

A Dacar Produções Cinematográficas, empresa responsável pelo filme, recorreu ao chefe do DPF, pedindo o reexame censório, que foi negado. Em seguida, por meio do produtor e protagonista de $A$ freira e a censura, David Cardoso, impetrou recurso no CSC. Nessa instância, o tratamento dispensado à obra foi bastante diferente. $\mathrm{O}$ relator do processo no Conselho, Geraldo Sobral Rocha, cineasta e exprofessor de cinema da Universidade de Brasília, buscou explicitar o que entendia como motivação política para a interdição. Segundo ele, em relatório apresentado ao plenário do órgão,

Estamos diante de um fato inegável: "A Freira e a Tortura" foi vítima, na DCDP, de censura insofismavelmente política. Motivos alegados pela turma de três Técnicos de Censura, que o examinou, são irrefutáveis quanto à motivação. Ainda que ali se alegue o desrespeito à religião católica e a ofensa à moral e aos bons costumes, os argumentos realmente fortes são a "ofensa à instituição policial" e o atentado à "segurança nacional e ao regime vigente" (Cx. 515, item 24343, 1984, AN/DF).

Ou seja, Sobral Rocha enfatizou, em sua defesa do filme, o conteúdo do parecer da censora Eni Martins França Borges, o único a falar abertamente das razões políticas para a interdição. A freira e a tortura foi, então, liberado para maiores de dezoito anos (em razão de suas cenas de violência), em uma reunião do CSC que também derrubou o veto da DCDP a sete canções, uma peça teatral e dois episódios de uma série de TV.

Esse processo foi, portanto, marcado por uma disputa discursiva em torno das razões da censura. A recente e controversa proibição de Pra frente, Brasil, indiscutivelmente por motivos políticos, desgastara a diretora da DCDP, sobretudo quando descoberta a sua atuação no sentido de descartar pareceres favoráveis à liberação do filme de Roberto Farias ${ }^{11}$. Hernandes empurrava o veto a A freira e a tortura para o campo da censura moral, historicamente normalizada no Brasil. Por outro lado, representantes da ala liberal do CSC tornaram, perante a opinião pública, uma interdição formalmente moral em um ato de censura política. Não sem embasamento, já que, conforme discutido anteriormente, a legislação censória utilizada no caso abria espaço para esse tipo de interpretação e outros filmes desse período encontraram obstáculos

\footnotetext{
${ }^{11}$ Em ata da reunião do CSC de 26 de agosto de 1982, aparece o relato do sumiço de pareceres favoráveis ao filme de seu processo censório, que teriam sido suprimidos pela diretora da DCDP: "O Senhor Presidente concede então a palavra ao Dr. Pompeu de Souza, que havia pedido vista, com mais 2 conselheiros, do filme "Pra frente Brasil", o qual solicitara ao Dr. Euclides Mendonça que encaminhe ao Ministro da Justiça uma representação, que lê e entrega, na qual aponta o desaparecimento de 4 pareceres de técnicos de censura que haviam sido visivelmente retirados do processo atinente ao caso, atitude que enquadrará o responsável no art. 314 do Código Penal; como o Conselho não possui atribuições administrativas, solicita ao Senhor Ministro que apure a irregularidade. O Senhor Presidente explica que, por delicadeza, o Dr. Pompeu de Souza lhe expusera o problema anteriormente, lembrando que uma denúncia de um suposto delito pressupõe tão somente a denúncia e que encaminhará ao Ministro para obter resposta; que anteciparia a primeira explicação da Diretora do DCDP, que lhe dissera que dentro do procedimento de exame de processos naquela Divisão que habitual é o exame de 3 censores e que informalmente introduzira mais técnicos na Comissão Especial; que já adotara o mesmo procedimento - supressão de pareceres dessa citada Comissão - em outros processos. O Dr. Pompeu de Souza lembra que o Dr. José Vieira Madeira, ex-diretor da DCDP, se limitava a repetir o $1^{\circ}$ despacho, já que o DiretorGeral do DPF, Coronel Moacir Coelho, lhe outorgara atribuição para revisão em 2a instância; que a Dra. Solange Hernandes criara a Comissão Revisora dessa instância e que se ela resolvera modificar esse rito, o fizera depois desse filme; que não esperava que ela admitisse que tirara as peças do processo". Solange Hernandes foi a público e confessou a retirada dos pareceres, ainda que se justificando a partir do mesmo argumento citado na ata: os referidos pareceres teriam sido produzidos a pedido dela própria, para além da obrigação legal do exame do filme por três censores; eles não fariam parte, portanto, do processo de Pra frente, Brasil. De qualquer maneira, a presença do assunto em grandes órgãos da imprensa escrita expôs Hernandes e a DCDP ao escrutínio público e a críticas. No entanto, o desgaste causado pelo caso Pra frente, Brasil não se restringiu ao lado censório: pouco depois do início da polêmica envolvendo a censura ao filme, Celso Amorim, então diretor-geral da Embrafilme, coprodutora do filme, foi afastado do cargo.
} 
na DCDP por motivos políticos (não só Pra frente, Brasil, como também A próxima vítima e Em nome da segurança nacional). O conselheiro pró-liberação agia, dessa forma, consciente dos esforços do próprio regime de negar a permanência da censura política no contexto da abertura. Mas, ao mesmo tempo, é possível aceitar que as motivações dos censores tenham sido primordialmente morais, considerando a já referida agressividade do tratamento dispensado à sexualidade no filme e a presença destacada, na narrativa, de uma personagem abertamente associada à Igreja Católica.

De acordo com Miliandre Garcia (2009, p. 52), o Ministro da Justiça Petrônio Portella estabelecera, quando da regulamentação do CSC em 1979, que "a censura de diversões públicas não mais se preocuparia em defender a segurança nacional e se limitaria a resguardar a moral e os bons costumes". No momento da censura de $A$ freira e a tortura, apesar do visível recrudescimento censório que caracterizava as gestões do Ministério da Justiça e da DCDP ${ }^{12}$, oficialmente a diretriz de Portella seguia valendo, algo explicitado em declaração de Euclides Mendonça ao jornal $O$ Globo, em maio de 1981:

Euclides Mendonça revelou que os critérios de liberação de filmes de cunho político não deverão ser alterados: "Desde que a obra não fira a Constituição, poderá ser liberada. Entramos num processo de abertura política e quem está na chuva é para se molhar" (CRAVO ALBIN, 2002, p. 68).

\footnotetext{
${ }^{12}$ Um exemplo: Ricardo Cravo Albin (2002, p. 66), conselheiro do CSC, relata o uso político das "Senhoras de Santana", movimento de mulheres de classe média de São Paulo, pelo ministro Abi-Ackel em 1981. Tais senhoras organizaram abaixo-assinados pedindo maior rigor da censura contra o que elas chamavam de "onda de pornografia" e foram recebidas pelo ministro, que as sugeriu que "procurassem o apoio de políticos, associações de classe, clubes e educadores para que a pressão da opinião pública pudesse obrigar as emissoras de televisão a melhorar o nível da programação". Além disso, Abi-Ackel teria prometido a elas que levaria o documento ao presidente Figueiredo e que pediria a ele que "baixasse decreto autorizando o ministro a nomear donas-de-casa, educadores e religiosos para o Conselho Superior de Censura". Mesmo se tratando de um caso em que a censura moral estava em voga, ele é sintomático dessa disposição de Abi-Ackel de tornar mais rígida a atuação da DCDP, inclusive entrando em conflito com o CSC. Algumas medidas do ministro, aliás, buscaram minar a atuação do Conselho: a troca de Octaviano Nogueira, considerado um liberal, por Euclides Mendonça, chefe de gabinete do próprio Abi-Ackel, na presidência do CSC; a proposição do aumento do número de conselheiros, garantindo a representação de mais setores contrários à abertura da censura; e a determinação à DCDP de que houvesse maior rigor na liberação de filmes e especialmente programas de $\mathrm{TV}$, alvo principal do moralismo de grupos como o das "Senhoras de Santana".
}

Vale fazer aqui, por fim, algumas breves considerações sobre essa diferenciação entre censuras moral e política. Beatriz Kushnir (2012, p.38) busca quebrar essa dicotomia ao estabelecer que, sob os discursos de proteção da moral e dos bons costumes e da defesa dos interesses da nação, toda censura é política. De fato, moral e bons costumes e assuntos mais estritamente políticos andavam lado a lado nas preocupações censórias, afinadas com a Doutrina de Segurança Nacional que embasou o regime militar no pós-1964, o que fica claro na legislação que regulamentou o setor a partir da década de 1940. Como aponta Kushnir (2012, p. 105-106), falando especificamente da Lei no $0.536 / 68$,

\begin{abstract}
[...] o artigo $3^{\circ}$ da 5.536/68, ao sentenciar que nenhuma manifestação poderia ser contrária às questões de política e segurança da nação, como também aos elementos de moral e bons costumes, expõe que a censura, nesse momento, era percebida sempre como um ato político, e não restrito apenas ao universo das diversões públicas. Tudo - do livro ao filme, do jornal à música, do teatro ao Carnaval - era objeto de censura: avaliação, aprovação ou proibição. Censurar, portanto, é um ato político em qualquer esfera ou instante de sua utilização. Com graus de ingerência maiores ou menores, esse ponto é fundamental para compreender os mecanismos estabelecidos no pós-AI-5.
\end{abstract}

A posição de Kushnir parece correta. Toda censura é um ato político e, no contexto de uma ditadura fortemente marcada pelos ideais de segurança nacional, em que toda manifestação comportamental que contrariasse os valores morais compartilhados pelos setores mais conservadores da população poderia ser enquadrada como tentativa de subversão da ordem política vigente, isso fica ainda mais explícito. No entanto, a separação entre censura moral e censura política parecia clara tanto para os profissionais da DCDP, no contexto da abertura, quanto para o público consumidor das chamadas diversões públicas. Algo, aliás, expresso enfaticamente na manifestação ao presidente José Sarney, em 1985, de uma cidadã assustada com a liberalidade da censura em tempos de redemocratização: "Essa abertura da censura, acho que é só para se tratar de política, mas pelo que estão entendendo [...], pensam eles que caiu a moral e os bons costumes" (FICO, 2002, p. 260). A mentalidade corrente, ou parte dela, acreditava, portanto, que continuaria sendo dever do setor censório coibir manifestações artísticas que ofendessem seus valores 
morais, mas não a proibição de quaisquer temas políticos. Esses estariam protegidos pela liberdade de expressão que passava a vigorar. Compreendendo isso, DCDP e CSC travaram a referida disputa em torno do real caráter da interdição de $A$ freira e a tortura.

\section{Considerações finais}

Em um momento de transição da ditadura militar para a democracia, a Divisão de Censura de Diversões Públicas, órgão responsável pela censura às artes, entre elas o cinema, agiu de forma ambígua. $\mathrm{Na}$ verdade, houve oscilação de sua postura em um intervalo temporal reduzido, em razão da passagem da gestão de José Vieira Madeira (1979-1981), mais liberal (alinhada com as diretrizes do então Ministro da Justiça, Petrônio Portella), à de Solange Hernandes, de forte viés conservador (como a de Ibrahim Abi-Ackel no Ministério da Justiça).

Foi justamente nessa transição que a DCDP teve de lidar com o desafio representado por Pra frente, Brasil, filme de grande apelo comercial que abordava temas politicamente espinhosos para o regime (tortura e desaparecimento de presos políticos, luta armada, envolvimento de empresários com a repressão, vinculação entre esquadrões da morte e agentes do Estado), ainda que de forma dúbia no último caso ${ }^{13}$.

Lançado pouco depois, A freira e a tortura, de Ozualdo R. Candeias, representou um novo teste para a suposta liberalização censória, por combinar em si crítica política e ataque aos valores entendidos pela censura como representativos da moral e dos bons costumes da família brasileira. O caso, ao lado dos de outros filmes do período (Pra frente, Brasil, Em nome da segurança nacional e $A$ próxima vítima), marcou a continuidade da existência de censura política às artes, prática que o regime dizia buscar abolir, bem como foi caracterizado por uma disputa entre DCDP e CSC sintomática das relações complexas entre moral e política no âmbito censório. A interdição de $A$ freira e $a$ tortura permite debater tanto a intersecção dessas duas esferas quanto a busca por sua separação nos estertores da ditadura militar brasileira.

Ao fim e ao cabo, o longo processo de abertura foi caracterizado por boa dose de incerteza, por avanços e retrocessos. Teve início ainda com o governo do general Ernesto Geisel (1974-1979) e avançou até o do general

\footnotetext{
${ }_{13}$ Sobre a dubiedade do discurso de Pra frente, Brasil em relação ao envolvimento do regime na tortura e desaparecimento de adversários políticos, Cf. GUEDES, 2014.
}

João Baptista Figueiredo (1979-1985). No campo dos avanços, podem ser citadas as eleições parlamentares de 1974, nas quais o MDB, partido de oposição ao regime, obteve expressiva vitória; a campanha pela anistia dos presos políticos, em fins dos anos de 1970, período que também viu a ascensão do novo movimento operário no ABC Paulista; a regulamentação do CSC em 1979; a vitória de políticos de oposição em importantes estados - Leonel Brizola no Rio de Janeiro, Tancredo Neves em Minas Gerais, Franco Montoro em São Paulo, José Richa no Paraná - nas eleições para governador de 1982; a campanha pelas eleições diretas para presidente da República em 1983/1984.

Já no campo dos retrocessos, podem ser lembradas as pressões dos setores militares radicais contra a abertura, que provocaram, por exemplo, a morte sob tortura do jornalista Vladimir Herzog, em 1975, e do operário Manuel Fiel Filho, em 1976; os ataques a bomba às sedes de instituições oposicionistas, como a Associação Brasileira de Imprensa (ABI) e a Ordem dos Advogados do Brasil (OAB), promovidos por estes mesmos grupos radicais, que seriam responsáveis também pelo atentado do Riocentro, em 1981; a Lei Falcão, lei eleitoral que restringia o acesso da oposição aos meios de comunicação, no contexto posterior às eleições de 1974; o Pacote de Abril, série de medidas adotadas pelo governo Geisel após desgastante impasse com a oposição em 1977; a Lei da Anistia imposta pelo governo em 1979, que livrou agentes da repressão de irem a julgamento; o recrudescimento da censura às diversões públicas a partir de 1981, com a gestão de Solange Hernandes na DCDP e de Ibrahim Abi-Ackel no Ministério da Justiça; a derrota da proposta de eleições diretas para presidente e a transição pactuada para a democracia através da eleição indireta do oposicionista moderado Tancredo Neves e do aliado histórico da ditadura José Sarney (TEIXEIRA DA SILVA, 2010).

Nesse sentido, não deixa de haver alguma coerência na ambiguidade da censura ao longo do último governo militar, mesmo dentro de uma mesma gestão da DCDP, em relação ao cinema político. Em tempos de transição, a censura também passou a agir segundo uma lógica da incerteza, respondendo de formas diversas a filmes que, aparentemente, receberiam dela um mesmo tratamento.

\section{Referências}

A OPÇÃO ou as rosas da estrada. Direção: Ozualdo R. Candeias. Produção: Zé Risonho, Alan Fontaine, Renato Petri, Virgílio Roveda e Ozualdo R. Candeias. Intérpretes: Carmen Angélica, Vilma Camargo, Nere de Passy, Jairo Ferreira e outros. 
Roteiro: Ozualdo R. Candeias. São Paulo: Embrafilme; Prodsul Produções Cinematográficas; Secretaria de Estado da Cultura do Governo de São Paulo, 1981. 1 VHS (88 min), p\&b. https://doi. org/10.17851/2317-2096.28.2.137-156

AS BELLAS da Billings. Direção: Ozualdo R. Candeias. Produção: Ozualdo R. Candeias. Intérpretes: Mario Benvenutti, Sílvia Gless, José Mojica Marins, Almir Sater, Nilza Inês e outros. Roteiro: Ozualdo R. Candeias. Música: Oswaldo R. Carrilho. São Paulo: Embrafilme, Ozualdo R. Candeias Produções Cinematográficas; Secretaria de Estado da Cultura do Governo de São Paulo, 1987. 1 VHS (90 min), color. https://doi.org/10.17771/pucrio.acad.32658

BOM burguês, O. Direção: Oswaldo Caldeira. Produção: Oswaldo Caldeira e Paulo Thiago. Intérpretes: José Wilker, Cristiane Torloni, Betty Faria, Jardel Filho, Nelson Xavier, Anselmo Vasconcelos e outros. Roteiro: Oswaldo Caldeira, Doc Comparato e Leopoldo Serran. Música: Paulo Moura. Rio de Janeiro: Encontro Produções Cinematográficas, 1983. 1 DVD (99 $\mathrm{min})$, color.

ARQUIVO NACIONAL (Brasil). Superintendência Regional de Brasília. Fundo Divisão de Censura de Diversões Públicas (DCDP). Brasília DF: DIBRAQ, 1972-1978.

BRASIL. Decreto no 20.493/46, de 24 de janeiro de 1946. Aprova o regulamento do Serviço de Censura de Diversões Públicas do Departamento Federal de Segurança Pública. Diário Oficial da União: Seção 1, Brasília, DF, p. 1456, 29 jan. 1946. https://doi.org/10.20396/rho.v10i38.8639704

BRASIL. [Constuição (1967)]. Constituição da República Federativa do Brasil de 1967. Diário Oficial da União: Seção 1, Brasília, DF, p. 1, 24 jan. 1967. https://doi. org/10.11606/d.2.2010.tde-13122010-160747

BRASIL. Lei $\mathrm{n}^{\circ}$ 5.536, de 21 de novembro de 1968. Dispõe sobre a censura de obras teatrais e cinematográficas, cria o Conselho Superior de Censura, e dá outras providências. Diário Oficial da União: Seção 1, Brasília, DF, p. 10177, 22 nov. 1968. https://doi. org/10.11606/t.27.2011.tde-28092011-175757

BRASIL. Decreto-Lei 1.077, de 26 de janeiro de 1970. Dispõe sobre a execução do artigo $153, \S 8^{\circ}$, parte final, da Constituição da República Federativa do Brasil. Diário Oficial da União: Seção 1, Brasília, DF, p. 577, 26 jan. 1970. https://doi. org/10.11606/d.2.2010.tde-13122010-160747

BRASIL. [Constuição (1967)]. Emenda Constitucional no 1, de 17 de outubro de 1969. Edita o novo texto da Constituição Federal de 24 de janeiro de 1967. Diário Oficial da União: Seção 1, Brasília, DF, p. 8865, 20 out. 1969. https://doi. org/10.5380/rfdufpr.v12i0.7157

CRAVO ALBIN, Ricardo. Driblando a censura: de como o cutelo vil incidiu na cultura. Rio de Janeiro: Gryphus, 2002.

DAMAS do prazer. Direção: Antonio Meliande. Produção: Alfredo Palácios e Maurício Palácios. Intérpretes: Irene Stefânia, Bárbara Fazio, Sueli Aoki, Nicole, Nadja Destro e outros. Roteiro: Ody Fraga. São Paulo: Kinoart Filmes; Companhia Cinematográfica Serrador; G.I.C. - Grupo Internacional Cinematográfico, 1978. 1 VHS (82 min), color.
E agora, José? Tortura do sexo. Direção: Ody Fraga. Produção: João Luiz Araújo e David Cardoso. Intérpretes: Arlindo Barreto, Luiz Carlos Braga, Pericles Campos, David Cardoso e outros. Roteiro: Ody Fraga. Música: Ronaldo Lark. São Paulo: Dacar Produções Cinematográficas, 1979. 1 VHS (90 min), color.

EM nome da segurança nacional. Direção: Renato Tapajós. Produção: Beth Ganymedes. Intérpretes: Adherbal Hercules, Amauri Alvarez, Alípio Freire, Carlos Cambraia, Carlos Seidl, Ênio Gonçalves e outros. Roteiro: Roberto Gervitz e Renato Tapajós. Música: Antônio Farigoul, Ralph Towner, Egberto Gismonti, Pink Floyd e Carl Off. São Paulo: Tapiri Cinematográfica, 1984. TV Rip (48 min), color.

FICO, Carlos. "Prezada Censura": cartas ao regime militar. Topoi, Rio de Janeiro, dezembro 2002, p. 251-286. https://doi. org/10.1590/2237-101x003005011

O FOTÓGRAFO. Direção: Jean Garrett. Produção: Ronald Marpin Dedekino e Jean Garrett. Intérpretes: Andrea Camargo, Carlos Casan, Castor Guerra, Claudete Joubert, Roberto Miranda e outros. Roteiro: Inácio Araújo e Jean Garrett. São Paulo: Brasil Internacional Cinematográfica; Cláudio Cunha Produções Cinematográficas; E.C. Filmes; Iris Filmes e Marte Filmes, 1980. 1 VHS (90 min), color.

A FREIRA e a tortura. Direção: Ozualdo R. Candeias. Produção: David Cardoso. Intérpretes: David Cardoso, Vera Gimenez, Claudia Alencar, Sergio Hingst, Edio Smanio e outros. Roteiro: Ozualdo R. Candeias. São Paulo: Dacar Produções Cinematográficas, 1983. HDTV Rip (89 min), color. Baseado na peça "O milagre da cela", de Jorge Andrade. https://doi. org/10.5216/rfd.v41i3.47160

GAMO, Alessandro; MELO, Luís Alberto Rocha. Histórias da Boca e do Beco. In: RAMOS, Fernão Pessoa; SCHVARZMAN, Sheila (org.). Nova história do cinema brasileiro. São Paulo: Edições Sesc São Paulo, 2018. https://doi.org/10.3368/ 1br.53.1.e1

GARCIA, Miliandre. A censura de costumes no Brasil: da institucionalização da censura teatral no século XIX à extinção da censura da Constituição de 1988. Rio de Janeiro: 2009. Trabalho apresentado à Coordenação-Geral de Pesquisa e Editoração - CGPE como parte dos requisitos necessários à conclusão da bolsa-pesquisador do Programa Nacional de Apoio à Pesquisa da Fundação Biblioteca Nacional. https://doi. org/10.22478/ufpb.1981-0695.2018v13n2.43385

O GOSTO do pecado. Direção: Cláudio Cunha. Produção: Cláudio Cunha. Intérpretes: Simone Carvalho, Jardel Mello, Maria Lúcia Dahl, John Herbert, Fábio Villalonga e outros. Roteiro: Inácio Araújo, Cláudio Cunha e Jean Garrett. Música: Mister Sam e Deymos. Rio de Janeiro: Claudio Cunha Cinema e Arte Ltda., 1980. 1 VHS (99 min), color. https://doi. org/10.25247/2447-861x.2018.n244.p197-207

GUEDES, Wallace Andrioli Guedes. Roberto Farias e a lógica do duplo-pensar no caso da censura ao filme 'Pra frente Brasil'. Topoi (Online): revista de historia, Rio de Janeiro, v. 15, p. 187-208, 2014. https://doi.org/10.1590/2237-101x015028007

GUEDES, Wallace Andrioli Guedes. O caso da interdição do filme 'Pra frente Brasil' e a continuidade da censura política 
às artes nos anos finais da ditadura militar brasileira. Revista Contemporânea, Rio de Janeiro, v. 1, p. 1-20, 2015. https://doi. org/10.1590/2237-101x015028007

GUEDES, Wallace Andrioli Guedes. A Próxima Vítima (1983), de João Batista de Andrade: a representação fílmica e a continuidade do arbítrio nos anos finais da ditadura militar brasileira. In: ENCONTRO REGIONAL DE HISTÓRIA DA ANPUH-MG: HISTÓRIA, DEMOCRACIA E RESISTÊNCIAS, 21., 2018, Montes Claros. Anais [....]. Montes Claros (MG): ANPUH MG, 2018. p. 1-8. Disponível em: http://www. encontro2018.mg.anpuh.org/resources/anais/8/1533681838 ARQUIVO_AProximaVitima(TextocompletoAnpuh2018).pdf. Acesso em: 09 out. 2019. https://doi.org/10.31893/2318-1265 jabb.v7n1p1-5

A HERANÇA. Direção: Ozualdo R. Candeias. Produção: Ozualdo R. Candeias, Antônio Alves Cury, Otávio Fernandes, Cleuza Rillo e Virgílio Roveda. Intérpretes: David Cardoso, Bárbara Fazio, Rosalvo Caçador, Américo Taricano, Deoclides Gouveia, Agnaldo Rayol e outros. Roteiro: Ozualdo R. Candeias. Música: Vidal França, Mario Litwin e Fernando Lona. São Paulo: Longfilm Produtora Cinematográfica, 1970. TV Rip (90 min), p\&b. Baseado na peça "Hamlet", de William Shakespeare. https://doi.org/10.22456/2236-6385.67431

KUSHNIR, Beatriz. Cães de guarda: jornalistas e censores, do AI-5 à Constituição de 1988. São Paulo: Boitempo, 2012.

LEME, Caroline Gomes. Ditadura em imagem e som: trinta anos de produções cinematográficas sobre o regime militar brasileiro. São Paulo: Editora Unesp, 2013. https://doi. org/10.11606/issn.2176-8099.pcso.2014.83620

A MARGEM. Direção: Ozualdo R. Candeias. Produção: Ozualdo R. Candeias, Antônio Alves Cury, Otávio Fernandes, Cleuza Rillo, Virgílio Roveda e Michael Saddi. Intérpretes: Mário Benvenutti, Valéria Vidal, Bentinho, Lucy Rangel, Tele Kare, Paulo Ramos, Brigitte Maier e outros. Roteiro: Ozualdo R. Candeias. Música: Luiz Chaves. São Paulo: Ozualdo R. Candeias Produções Cinematográficas; Produtora Nacional de Filmes, 1967. 1 DVD (96 min), p\&b. https://doi.org/10.11606/t.27.2013. tde-06052014-105039

MEU nome é Tonho. Direção: Ozualdo R. Candeias. Produção: Ozualdo R. Candeias, M. Augusto de Cervantes, Nilza de Lima e Manoel A. S. Ferreira. Intérpretes: Jorge Karan, Bibi Vogel, Nivaldo Lima, Eddio Smanio, Walter Portela, Tony Carli e outros. Roteiro: Ozualdo R. Candeias. Música: Paulinho Nogueira. São Paulo: Ibérica Filmes, 1969. 1 DVD (95 min), p\&b. https://doi.org/10.11606/t.27.2013.tde-06052014-105039

MULHER, mulher. Direção: Jean Garrett. Produção: Manuel Augusto Sobrado Pereira. Intérpretes: Helena Ramos, Carlos Casan, Petty Pesce, Cavagnole Neto, Aldo Bueno, Zelia Toledo e outros. Roteiro: Ody Fraga e Jean Garrett. Música: Aluizio Pontes. São Paulo: Maspe Filmes, 1979. HDTV Rip (95 min), color.

A MULHER que inventou o amor. Direção: Jean Garrett. Produção: Cassiano Esteves. Intérpretes: Aldine Muller, Rodolfo Arena, Ricardo Angelini, Carlos Arena, Theresa Bianchi e outros. Roteiro: João Silvério Trevisan. Música: Aluizio Pontes. São Paulo: E.C. Filmes; Marte Filmes, 1979. HDTV Rip (99 min), color.
ALMEIDA NETO, Américo R. de; TOLENTINO, Célia. Mestre Candeias: o homem e seus filmes. Baleia na Rede: Revista online do Grupo de Pesquisa e Estudos em Cinema e Literatura, Marília (SP), n. 1, n. 4, p. 152-162, 2007. Disponível em: http://www2.marilia.unesp.br/revistas/index.php/baleianarede/ article/view/1401. Acessoem: 09 out. 2019. https://doi. org/10.36311/1984-8900.2018.v10.n25.03.p22

NUNCA fomos tão felizes. Direção: Murilo Salles. Produção: Mariza Leão e Murilo Salles. Intérpretes: Roberto Battaglin, Cláudio Marzo, Susana Vieira, Meiry Vieira, Ênio Santos e outros. Roteiro: Alcione Araújo, Jorge Durán e Murilo Salles. Música: Sergio Saraceni. Rio de Janeiro: Cinefilmes, Embrafilme; Imacom Comunicação; Luiz Carlos Barreto Produções Cinematográficas; Morena Filmes; Movi\&Art; Salles \& Salles, 1984. 1 DVD (91 min), color. https://doi. org/10.4337/9781781002995.00011

O PALÁCIO de Vênus. Direção: Ody Fraga. Produção: M. Augusto de Cervantes. Intérpretes: Arlindo Barreto, Sérgio Boldrin, Wilson Bonifácio, Lola Brah, Eudes Carvalho, Jaime Cortez e outros. Roteiro: Ody Fraga. São Paulo: Maspe Filmes, 1980. TV Rip (83 min), color.

PAULA: A história de uma subversiva. Direção: Francisco Ramalho Jr. Produção: Sylvio Band, Stefan Burstini e Cid Gomes Fernandes. Intérpretes: Sheila Agnelli, Regina Braga, Armando Bogus, Carlos Cambraia Carina Cooper e outros. Roteiro: Francisco Ramalho Jr. e Consuelo de Castro. Música: Caribé da Rocha. São Paulo: Embrafilme; Oca Cinematográfica e Secretaria de Cultura do Estado de São Paulo, 1979. 1 DVD (93 min), color. https://doi.org/10.11606/issn.2318-8235.v79i0p373-379

PRA frente, Brasil. Direção: Roberto Farias. Produção: Riva Farias, Roberto Farias e Rogério Farias. Intérpretes: Reginaldo Faria, Antonio Fagundes, Carlos Zara, Natália do Vale, Elizabeth Savalla, Paulo Porto, Claudio Marzo e outros. Roteiro: Reginaldo Faria, Roberto Farias e Paulo Mendonça. Música: Egberto Gismonti. Rio de Janeiro: Produções Cinematográficas R. F. Farias Ltda.; Embrafilme, 1982. 1 DVD (105 min), color. https://doi.org/10.1590/2237-101x015028007

PROFISSÃO: mulher. Direção: Cláudio Cunha. Produção: Marcos Cunha. Intérpretes: Simone Carvalho, Mário Cardoso, Claudio Marzo, Lady Francisco, Wilma Dias e outros. Roteiro: Astolfo Araújo, Cláudio Cunha e Márcia Denser. Música: Luiz Guedes e Thomas Roth. Rio de Janeiro: Claudio Cunha Cinema e Arte, 1982. Web DL (101 min), color. https://doi.org/10.1109/ iv.2002.1028772

PRÓXIMA vítima, A. Direção: João Batista de Andrade. Produção: Wagner Carvalho e Assunção Hernandes. Intérpretes: Antonio Fagundes, Othon Bastos, Gianfrancesco Guarnieri, Louise Cardoso, Mayara Magri e outros. Roteiro: João Batista de Andrade e Lauro César Muniz. Música: Marcus Vinícius. São Paulo: Beca Produtores de Filmes; Embrafilme; Raíz Produções Cinematográficas; Taba Filmes e Álamo, 1983. HDTV Rip (98 min), color. https://doi.org/10.17655/9788567211121

RUA chamada Triumpho 969/70, A. Direção: Ozualdo R. Candeias. Produção: Jorge Alberto M. Teixeira, Antonio Roberto de Godoy e Cesário Felfeli. Intérpretes: Fábio Perez. Roteiro: Ozualdo R. Candeias. Música: Vidal França. São Paulo, 1971. 1 DVD (11 min), p\&b. 
SIMÕES, Inimá. Roteiro da Intolerância: a censura cinematográfica no Brasil. São Paulo: Editora SENAC, 1999.

TCHAU, amor. Direção: Jean Garrett. Produção: Jean Garrett, Luiz Carlos Lee, José Sacalina, Sylvio Borges Sacalina e Antônio Carlos Terranova. Intérpretes: Antonio Fagundes, Aparecida Braidotti, Abel Constâncio, Genílson de Souza, Ricardo Deneses e outros. Roteiro: Inácio Araújo e Jean Garrett. São Paulo: Embrapi, 1982. 1 VHS (95 min), color.

TEIXEIRA DA SILVA, Francisco Carlos. Crise da ditadura militar e o processo de abertura política no Brasil, 1974-1985. In: FERREIRA, Jorge; NEVES, Lucília de Almeida. O Brasil republicano, v. 4: "O tempo da ditadura". Rio de Janeiro: Civilização Brasileira, 2003. https://doi.org/10.29327/7.2390

VISITA do velho senhor, A. Direção: Ozualdo R. Candeias. Produção: Valêncio Xavier. Intérpretes: José Maria Santos e Marlene Araújo. Roteiro: Ozualdo R. Candeias. Curitiba: Fundação Cultural de Curitiba, 1976. 1 DVD (13 min), p\&b. https://doi.org/10.17771/pucrio.acad.32658

ZÉZERO. Direção: Ozualdo R. Candeias. Produção: Ozualdo R. Candeias. Intérpretes: Milton Pereira, Isabel Antinópolis, Maria Gizelia, Palmira B. de Almeida, Maria das Dores Oliveira e outros. Roteiro: Ozualdo R. Candeias. São Paulo, 1974. 1 DVD (30 min), p\&b. https://doi.org/10.22475/rebeca.v3n1.325

Recebido em: 15/2/2019.

Aprovado em: 28/6/2019.

Publicado em: 25/11/2019.

\section{Endereço para correspondência:}

Wallace Andrioli Guedes

Universidade Federal de Juiz de Fora (UFJF)

Rua José Lourenço Kelmer, s/n. - São Pedro

36036-900, Juiz de Fora, MG, Brasil

\section{Autor/Author:}

WALLACE ANDRIOLI GuEDES wguedes2004@yahoo.com.br

- Doutor em História Social, Universidade Federal Fluminense (UFF). Pós-doutorando em História pela Universidade Federal de Juiz de Fora (UFJF), Juiz de Fora, MG, Brasil. (iD) http://orcid.org/0000-0003-2929-6493

- PhD in Social History, Fluminense Federal University (UFF). Post-doctorate in History, Federal University of Juiz de Fora (UFJF). Juiz de Fora, MG, Brazil.

- Doctor en Historia Social, Universidad Federal Fluminense (UFF). Post-doctorando, Universidad

Federal de Juiz de Fora (UFJF). Juiz de Fora, MG, Brasil. 